\title{
The medical treatment of ulcerative colitis
}

\author{
GeOFFREY WATKINSON
}

\author{
Consultant Physician to the York Hospitals
}

The ADEQUATE treatment of any illness depends primarily upon a knowledge of its aetiology and in a chronic relapsing illness, such as ulcerative colitis, an awareness of its natural history and complications. While the final cause of ulcerative colitis remains obscure, increasing knowledge of possible causal factors and of the prognosis of the condition has markedly influenced its treatment in recent years.

When colitis was thought to be of bacterial origin specific sera were prepared but proved of no lasting value. Similarly, no effective agents to inhibit mucinases have been evolved. Enthusiasts for the hypothesis that colitis is due to food allergy have advocated the use of milk-free diets in colitic patients with apparent benefit (Andresen, 1942 ; Wright \& Truelove, 1965a, b). Attempts to suppress supposed autoimmune reactions have been made with corticosteroids used orally, topically or parenterally, by non-specific anti-inflammatory agents, such as sulphasalazine or more recently by immunosuppressive agents. Physicians impressed by psychosomatic factors in the illness have advocated the use of psychotherapy, of sedatives and antidepressant drugs and even leucotomy to control the condition.

Assessment of the value of any therapeutic measure proves difficult in a disease which varies greatly in severity and extent, not only from patient to patient but in the same individual from attack to attack, making rigorous controlled trials of any measure necessary in large groups of colitic patients before its values can be accepted.

Increasing knowledge of the nutritional and biochemical problems encountered in these patients, together with the introduction of more potent drugs, such as sulphasalazine and corticosteroids and the wider use of surgery, have materially improved the prognosis of ulcerative colitis in the last two decades.

\section{Principles of medical treatment}

The duties of a physician treating a patient with ulcerative colitis can simply be stated: (i) To terminate the acute colitic attack or relapse as quickly as possible.

(ii) To attempt by some form of maintenance therapy to prevent relapses or complications of the disease.

(iii) By a knowledge of factors known to influence the natural history and prognosis of colitis, to recognize that medical treatment has failed to induce remission or to prevent relapses or complications and to refer the patient for urgent or elective surgery.

The physician has to accept, as Bargen (1961) has emphasized that 'control' of colitis is far more likely than 'cure' and that the patient must be supported through long weeks, months or $\stackrel{\mathbb{\Phi}}{\mathbb{D}}$ years of chronic and often recurrent illness. Thiso is best done by a patient and persevering phys- $\mathbb{D}$ ician who works in close association with a sur $\frac{0}{0} \overrightarrow{0}$ geon interested and skilled in the difficult colonic surgery that colectomy in an acutely ill colitic patient may demand. Throughout a combined medico-surgical approach should be adopted both in the day-to-day management of acute attacks and through months and years of followup of the chronic case at a colitis clinic run jointly by a physician and surgeon. It has been suggested that a psychiatrist should complete the team to cope with the frequent psychosomatic problems which afflict these patients. While this is a debatable issue such a team obtained excellent results in the paediatric clinic of a Michigan hospital (McDermott, John \& Finch, 1964).

\section{Treatment of the acute attack}

The measures used in treating severe initial colitic attacks and relapses are summarized in Table 1 below.

\section{Rest}

Bed rest is recommended for any colitic relapse and early hospitalization for patients with severe diarrhoea, copious bloody stools, fever anaemia and weight loss. More adequate rest will be aided by the administration of sedative and tranquillizing drugs, such as phenobarbitone and 
amylobarbitone. In more anxious or obsessional patients meprobamate, chlordiazepoxide or diazepam can be tried and where agitation is complicated by nausea and vomiting, drugs such as promethazine hydrochloride or chlorpromazine can be used. Adequate sleep is essential often making hypnotics, such as chloral hydrate, amylobarbitone, pentobarbitone or gluthemide, necessary.

\section{TABLE 1}

Medical treatment of ulcerative colitis

REST
Bed rest-hospitalization
Sedative and tranquillizing drugs
Hypnotics
COLONIC REST
Parenteral feeding
Fluid diet
Low-residue, high-protein diet
Antispasmodic and antidiarrhoeal drugs
MAINTENANCE OF NUTRITION AND OF FLUID AND
ELECTROLYTE BALANCE
Replacement of fluid
Mineral replacement salt, potassium, magnesium, calcium
Vitamin supplements
Parenteral feeding
Anabolic agents
CORRECTION OF ANAEMIA
Oral, parenteral, intravenous iron
Blood transfusion
DIET
Low roughage, high-protein diet
Milk free diet on Occasion
ANTIBIOTICS
Used with caution, best given parenterally
Penicillin and streptomycin
Ampicillin, chloramphenicol
Neomycin
MORE SPECIFIC REMEDIES
Sulphasalazine
Orally
Topically
Coticosteroids
Parenterally
Orally
Topically
TREATMENTS UNDER EVALUATION
Rectal hypothermia
Leucotomy

\section{Colonic rest}

Colonic rest is achieved by dietary means and by various antispasmodic and antidiarrhoeal drugs. In the severely ill patient with continuous diarrhoea complete withdrawal of oral fluid and feedings is justified, the patient being maintained by parenteral fluids. Later a fluid diet and finally a low residue high protein diet are given.

A wide variety of antispasmodic drugs can be given and if used in dosage sufficient to produce mild side-effects will often control both diarrhoea and cramping abdominal pains. They are contraindicated in patients with glaucoma or previous urinary retention and if given in excessive dosage to severely ill patients may induce intestinal atony simulating a toxic megacolon.

Belladonna given as the tincture or in a sustained release tablet (Belladenal retard or Donnatal) can be used or one of the numerous synthetic anticholinergic drugs available, such as propantheline bromide, poldine methylsulphate, methscopolamine bromide or penthionate bromide, exhibited.

For the control of copious diarrhoea the use of opiates is justified provided it is realized that these drugs have addictive properties, may mask perforation or worsen ileus and, therefore, should only be prescribed for short periods and tapered off as soon as possible. Codein phosphate tablets, tincture of opium or tincture of chloroform and morphia can be given. Lomotil is a useful proprietary tablet combining a codein derivative diphenoxylate hydrochloride with atropine sulphate.

Thickening of the stools with bulk-forming laxatives seems to improve sphincter control while a few patients with proctocolitis may need mild laxatives as they are in fact constipated. Hydrophilic agents, such as psyllium seeds or methlcellulose, are used with or without mild laxatives, such as milk of magnesia, liquid paraffin or standardized senna.

\section{Maintenance of nutrition and of fluid and electro- lyte balance}

In acute fulminating attacks gross dehydration and profound electrolytic and metabolic imbalances may develop making it vital that such cases be managed in hospital where adequate biochemical facilities are available together with the trained nursing and house officer staff to cope with the intensive care which these cases may require.

In severe attacks gross dehydration with a hyponatraemic, hypokalaemic acidosis may develop making it necessary to rapidly correct these deficiencies with intravenous $5 \%$ dextrose, $0.9 \%$ sodium chloride $(150 \mathrm{mEq} / \mathrm{l})$ or $\frac{1}{6} \mathrm{M}$-lactate and adding potassium chloride $1.5 \mathrm{~g}(20 \mathrm{mEq})$ to each $500 \mathrm{ml}$ of infusion fluid. Potassium depletion may be profound and up to $80 \mathrm{mEq}$ daily may have to be given. Magnesium depletion may develop and is becoming more widely recognized as facilities for its estimation become more widely available.

Subsequently additional salt and potassium can 
be given orally as enteric coated tablets or as effervescent tablets $(1 \mathrm{~g}=6.5 \mathrm{mEq})$ of potassium. Reports that such tablets may cause intestinal ulceration have led to the use of liquid preparations of the chloride $(6.5 \mathrm{mEq} / \mathrm{g})$, the citrate $(9.2 \mathrm{mEq} / \mathrm{g})$ or the gluconate $(20 \mathrm{mEq} / 15 \mathrm{ml})$. Unfortunately, many of these preparations are unpalatable and may cause diarrhoea in which case a slow release tablet incorporating $600 \mathrm{mg}$ of potassium chloride $(8 \mathrm{mEq})$ in a slow release wax core is administered in a dosage of four to eight tablets daily.

Vitamin replacement is necessary in many severely ill and debilitated patients. Supplements of vitamins A and D (calciferol), B complex and C (parentrovite), cyanocobalamin and folic acid and vitamin $\mathrm{K}$ may have to be given intravenously or intramuscularly, particularly if complicating liver disease is present. Subsequent adequate oral replacement is given.

Intravenous protein replacement may have to be attempted in critically ill patients using whole blood, double strength plasma or protein hydrolysates (Amigen, Trophysan) supplying additional calories with glucose or fat emulsions (Lipiphysan). Such infusions should be cautiously used as they may cause systemic reactions and phlebitis locally. Similarly, claims have. been made that anabolic steroids, given intramuscularly, may accelerate weight gain and improve appetite in colitic patients (Kasisch, 1963).

\section{Correction of anaemia}

Anaemia may need to be corrected in both the acute and chronic phase of the disease. Blood transfusion is often urgently required for massive blood loss or to correct the anaemia and hypoproteinaemia of the chronic case. Oral iron therapy may be poorly tolerated by the colitic patient, making it necessary to use a liquid preparation, an enteric coated or sustained release tablet or to give iron intramuscularly or intravenously.

\section{Antibiotics}

Antibiotics should be used with caution in ulcerative colitis as their oral administration may worsen diarrhoea and predispose to secondary infection with monilial organisms. Used discriminately and given parenterally to the acutely ill febrile patient they may dramatically improve the patient's condition. A combination of penicillin and streptomycin is best tried initially. Alternatively, intramuscular tetracycline, chloramphenicol or ampicillin can be given. Neomycin or succinylsulphathiazole, given orally, will often produce improvement and are useful pre-operatively.
Diet

Rapid wasting occurs in both acute and chronic attacks with hypoproteinaemia, vitamins and nutritional deficiencies. It is therefore important that the patient eats as much of a high-protein low-residue diet as his condition allows supplying $2500-3500 \mathrm{cal}$ daily with $100-150 \mathrm{~g}$ of protein presented as attractively as possible. This diet is most widely used in ulcerative colitis.

The role of milk allergy in the pathogenesis of colitis was first suggested by Andresen (1942) and by Rowe (1942). Interest in the topic was re-awakened by Truelove (1961) who reported on a small group of patients who became symptom free on a milk-free diet and who relapsed when milk was introduced into the diet. Recently Wright \& Truelove (1965a) have reported favourably on the results of a controlled trial of a milk-free diet in twenty-six colitic patients who faired better on a milk-free diet than twenty-four colitic patients receiving a normal or gluten-free diet. Twice as many patients on a milk-free diet remained symptom free and fewer patients suffered severe relapses, differences between the groups being only marginally significant. Wright and Truelove estimate that approximately one in five patients with ulcerative colitis will benefit from milk restriction, a proportion which may be greater in first attacks of the disease. Regrettably, raised titres of circulating antibodies to milk provided no guide to the possible response of a colitic patient to a milk-free diet, making it impossible to select patients who might benefit from withholding milk. It will be of considerable interest to see if these results can be confirmed on a larger group of patients and the use of a milk-free diet cannot at present be routinely advocated.

\section{Psychotherapy}

One of the most controversial aspects of the treatment of ulcerative colitis is the role of psychotherapy. First advocated by Murray in 1930, psychotherapy has found many enthusiastic supporters through the years (Paulley, 1950; Grace \& Wolff, 1951; Grace \& Graham, 1952; Groen, 1961). These authors advocate that a constructive patient-physician relationship should be established where the patient is encouraged to discuss their symptoms and their personal and environmental difficulties with a physician who gives the patient 'time, kindness, tangible signs of understanding and support' and who is 'available at all times by phone', 'as often as daily' if the patient's condition demands it. Such a relationship makes exacting, exhausting and prolonged demands on the physician who 
is only able to treat a limited number of colitic patients at one time or even in his working life.

Other physicians have had less fortunate experiences with formal psychotherapy in ulcerative colitis. Crohn \& Yarnis (1951), reporting that only one of twelve patients so treated obtained benefit while two colonic perforations occurred during active psychotherapy.

It follows that if psychotherapy is to be practised it must be used by or in close association with a physician skilled in the management of colitic patients who is capable of recognizing the dangerous and potentially lethal complications of the condition. In these circumstances in chronic relapsing cases psychotherapy is often rewarding but there is certainly no place for expert psychotherapy in isolation.

\section{Sulphasalazine}

Sulphasalazine (salazopyrin or azulfidine) is a diazo compound of salicylic acid and sulphapyridine and has been used successfully in the treatment of ulcerative colitis since its development in Sweden in 1941 by Svartz and is capable of inducing remissions in a significant proportion of patients treated (Svartz, 1956, 1961 ; Moertal \& Bargen, 1959 ; Watkinson, 1961a, b, 1962 ; Truelove, Watkinson \& Draper, 1962; Morrison 1963). The drug's mode of action is unknown; it has an affinity for connective tissue throughout the body and reaches high concentrations in serous fluids, liver and intestinal wall. It has no effect on the intestinal flora and seems to exert its beneficial effect by a non-specific antiinflammatory action in the colonic wall and lumen.

Dosage can be varied with the severity of the attack; plain tablets containing $0.5 \mathrm{~g}$ are given initially reserving the enteric-coated tablets for patients exhibiting gastro-intestinal intolerance to the plain tablets. Usually two to four tablets four to six times daily are used, depending on the tolerance of the patient. Unfortunately, in about $20 \%$ of patients receiving sulphasalazine unpleasant side effects will develop. Nausea, vomiting and headache are most common and are usually controlled by substituting the enteric-coated tablet in the same dosage. Rarely drug fever, skin rashes, muscular pains, leucopenia, acute haemolytic anaemia or even agranulocytosis may develop and call for an immediate cessation of therapy, though in a proportion it may be possible to cautiously re-introduce the drug later. It follows that therapy should be monitored initially by frequent blood counts during the period of intensive therapy.

Results obtained by various workers in treat- ing acute attacks of the disease are summarized in Table 2 below. In the 861 patients reviewed, remission or improvement occurred in between $47 \%$ and $78 \%$ of those treated while side effects developed in between $16 \%$ and $45 \%$. Mucosal improvement on sigmoidoscopy has been reported in $43 \%$ of fifty-eight patients treated (Truelove et al., 1962). Salazopyrin, therefore, emerges as a useful drug in the treatment of all types of colitis with better than even chances of success. Side effects somewhat limit the value of the drug, many of which can be overcome by the use of enteric-coated tablets, which, incidentally, have still to be shown as effective as the plain tablets by further clinical trials.

A chemical analogue of sulphasalazine, salicylazosulphadimethyl-pyrimidine (azudimidine) was submitted to limited trials with conflicting results by several workers, most finding the drug to be less effective and more toxic than sulphasalazine (Braders \& Bargen, 1960 ; Baron et al., 1962a ; Watkinson, unpublished data 1967). For this reason the manufacturers have withdrawn this compound.

Sulphasalazine incorporated into a suppository containing $1 \mathrm{~g}$ of the drug has recently been shown by controlled trials to exert a beneficial topical action if inserted nightly in patients with distal proctocolitis, fifteen of eighteen patients receiving potent suppositories going into clinical remission as compared with five of eighteen treated by insert suppositories. No side effects were observed (Watkinson, unpublished data 1967).

\section{TABLE 2}

Immediate results of treatment with sulphasalazine of acute colitic episodes in 861 patients treated in Sweden, America and England, together with the frequency of drug intolerance

\begin{tabular}{|c|c|c|c|}
\hline & $\begin{array}{l}\text { Patients } \\
\text { treated }\end{array}$ & $\begin{array}{l}\% \text { recovered } \\
\text { or much } \\
\text { improved }\end{array}$ & $\begin{array}{c}\% \text { showing } \\
\text { drug } \\
\text { intolerance }\end{array}$ \\
\hline Svartz $(1956,1961)$ & 439 & 77 & 'Few' \\
\hline Morrison (1963) & 60 & 70 & 21 \\
\hline Moertal \& Bargen (1959) & 133 & 64 & 17 \\
\hline Watkinson (1961a) & 69 & 47 & 16 \\
\hline $\begin{array}{l}\text { Truelove, Watkinson \& } \\
\text { Draper (1962) }\end{array}$ & 58 & 50 & 22 \\
\hline Dick et al. (1964) & 32 & 78 & 45 \\
\hline $\begin{array}{l}\text { Lennard-Jones et al. } \\
\text { (1960) }\end{array}$ & 20 & 65 & 40 \\
\hline
\end{tabular}

\section{Corticosteroids}

The value of corticosteroids in ulcerative colitis remained in doubt for some years, but in the last 15 years a number of carefully controlled trials have demonstrated that steroids, whether used systemically or topically, are capable of 
inducing remissions in a significant proportion of patients treated. They have emerged as a valuable adjuvant in therapy capable, on occasion, of producing remarkable remissions but regrettably often failing unpredictably to control acute attacks of colitis or to prevent relapse or the development of complications. Whether their beneficial effects are due to a reduction of the vascular and tissue responses to inflammation or a damping down of autoimmune or hypersensitivity reactions in the bowel wall is not known.

The indications for systemic treatment with steroids have been reviewed elsewhere (Watkinson, 1966). They should be used in any severe colitic attack or relapse which is not controlled by simple measures particularly when associated with systemic colitic complications, such as arthritis, skin or eye lesions known to be improved by steroids. They should be used with caution in patients with established electrolyte disturbances, malnutrition, marked abdominal distension or rectal bleeding or if coincident disease known to be worsened by steroids is present, such as diabetes, tuberculosis or peptic ulcer. The drugs are contra-indicated if perforation or peritonitis are suspected, if a toxic megacolon has developed or if severe perianal disease is present.

The dosage and method of administration will vary with the severity of the attack. In fulminating disease ACTH will produce more remissions than cortisone particularly if administered intravenously initially and followed by the intramuscular injection of 40-80 units of ACTH gel twice daily. As the patient improves dosage is gradually tailed off and oral steroids substituted. Hydrocortisone $50 \mathrm{mg}$ intravenously and 50 $100 \mathrm{mg}$ intramuscularly 8-hourly produces comparable results and has a more rapid onset of action. In cases of moderate severity cortisone acetate $150-300 \mathrm{mg}$ is given orally and produces rather fewer remissions than does ACTH, possibly because of poor intestinal absorption. For milder attacks in ambulatory patients prednisoneon $20-60 \mathrm{mg}$ daily is used initially with a reduction to $10-15 \mathrm{mg}$ as improvement occurs.

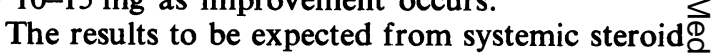
therapy are summarized in Table 3 below. In controlled trials conducted between 1950 and $\Rightarrow$ 1959 (Truelove \& Witts, 1955, 1959) it was shown that the $40 \%$ remission rate induced in 109 colitis? patients receiving $100 \mathrm{mg}$ daily of cortisone was $\frac{\bar{c}}{\mathrm{c}}$ significantly better than the $16 \%$ remission rate $\frac{\omega}{\sigma}$ induced in 101 patients receiving inert tablets. $\mathscr{\complement}$ First attacks, at all grades of severity, fared better than chronic relapsing cases where remis- $\vec{\circ}$ sion rates were 42 and $26 \%$, respectively. In a second trial it was shown that no better results $\vec{\omega}$ were achieved by doubling the dose of cortisone? to $200 \mathrm{mg}$ daily, where again two out of everyo five patients treated went into remission. However, a significantly higher remission rate was $\vec{f}$ obtained in eighty-four patients treated by $80 \mathrm{cr}$ units of ACTH daily where $61 \%$ went into remission, relapsing cases faring better than first 8 attacks, remission rates being 71 and $50 \%$, respectively. Similar results have been achieved by many workers throughout the world, for example, $\vec{e}$ the Chicago group had treated 340 patients wi steroids up to 1962 and report an immediate $\overrightarrow{\mathbb{D}}$ favourable response in $20 \%$ of those treated and 3 sustained improvement in $73 \%$ (Spencer et al , 1962). Where it was shown in the trials of Truof $\overrightarrow{0}$ love \& Witts $(1955,1959)$ that steroids bot. halved the mortality and recourse to surgery those treated many limitations of therapy emerged: Perianal suppurative conditions occurred three times more commonly in the steroidtreated group making it desirable to combine steroids with either suphasalazine or a parenterally administered antibiotic.

While some authorities (Brooke, 1956) have claimed that steroids may actually induce colonic perforation and certainly mask its presence, in the controlled trial reported by Truelove $\&$

TABLE 3

Results of steroid treatment in ulcerative colitis

\begin{tabular}{lccccc}
\hline & Daily dose & No. patients & \multicolumn{3}{c}{ Remission rates (\%) } \\
\cline { 5 - 6 } & & & All cases & First attacks & Relapses \\
\hline Cortisone* & $100 \mathrm{mg}$ & 109 & 41 & 42 & 26 \\
Inert & - & 101 & 16 & 13 & 17 \\
Cortisone* & $200 \mathrm{mg}$ & 85 & 39 & 42 & 37 \\
ACTH & $80 \mathrm{units}$ & 84 & 61 & 50 & 71 \\
Cortisone and ACTH† & $200-300 \mathrm{mg}$ & 340 & 68 & - & - \\
\hline
\end{tabular}

*Truelove \& Witts $(1955,1959)$.

†Spencer et al. (1962). 
Witts (1955) the frequency of perforation was greater in the group not treated by steroids. This contention was supported by Goldgraber and others in 1957 and later by our own study of the frequency of perforation in 165 patients studied over a 10-year period which showed the frequency of perforation to be identical in groups of patients receiving and not receiving steroids with frequencies of 4.3 and $4.1 \%$, respectively (de Dombal et al., 1965a). There is little evidence therefore, to suggest that steroids predispose either to perforation or to massive colonic haemorrhage, while the frequency of postoperative complications and collapse was greater in groups of patients treated preoperatively with steroids than in those not receiving them. Differences were not satisfactorily significant and the data difficult to appraise because of the greater perforation of seriously ill patients in the steroid group (Watts et al., 1966a, b ; Lennard-Jones \& Vivian, 1960).

\section{Topical treatment of colitis with corticosteroids}

Steroids were first used topically in colitis by Truelove in 1956 and their value in distal disease confirmed by a series of controlled trials (Truelove, 1958 ; Watkinson, 1958, 1961a, b ; Matts, 1960, 1962; Matts \& Gaskell, 1961; Spencer \& Kirsner, 1962 ; Patterson et al. 1965). The major attractions of this method of treatment are that minimal or no side-effects develop, and it is possible to obtain much higher concentrations of steroid locally than could be achieved by systemic therapy.

Its disadvantages are that the method may prove cumbersome and distasteful to many patients while those with profuse diarrhoea may be unable to retain the enemata adequately.
The dosage, relative potencies, method of administration, limitations and advantages together with the results of various types of topical steroid therapy are shown in Table 4 below.

Freshly prepared hydrocortisone hemisuccinate sodium can be administered by rectal drip, may penetrate to the right colon and have a beneficial effect in 52-69\% of the patients treated (Truelove, 1958 ; Patterson et al., 1965 ; Watkinson, 1961a). The stability of prednisolone 21phosphate enabled it to be administered from disposable enema bags as a retention enema and remission rates of $75-88 \%$ were claimed in patients with distal disease (Matts \& Gaskell, 1961 ; Patterson et al., 1965 ; Spencer \& Kirsner, 1962). While betamethazone, a steroid fifty times more potent than cortisone, given in doses of 5-10 $\mathrm{mg}$ as a retention enema produced remissions in four-fifths of patients treated, side-effects were frequent and severe and led to the withdrawal of this type of enema by the manufacturers (Matts, 1962). It is possible that the new steroid betamethasone-17-valerate (betnovate) which has enhanced topical and reduced systemic effects now under evaluation given in tablet form or as a retention enema may prove as effective as preliminary trials have suggested (Gill et al., 1965).

Steroids can be most conveniently administered topically as suppositories containing prednisolone or betnovate and have been proved by controlled trials to improve patients with distal proctocolitis (Truelove, 1959 ; Patterson et al., 1965 ; LennardJones et al., 1962).

Topical steroid treatment therefore emerges as a most useful form of therapy, most applicable to mild cases of colitis with distal disease or proctocolitis.

TABLE 4

Topical use of steroids in ulcerative colitis

\begin{tabular}{|c|c|c|c|c|c|c|}
\hline \multirow[t]{2}{*}{ Type of steroids } & \multirow{2}{*}{$\begin{array}{c}\text { Dosage } \\
(\mathrm{mg})\end{array}$} & \multirow{2}{*}{$\begin{array}{c}\text { Method of } \\
\text { administration }\end{array}$} & \multirow[t]{2}{*}{ Advantages } & \multirow{2}{*}{ Disadvantages } & \multicolumn{2}{|c|}{ Remission } \\
\hline & & & & & No. & $\%$ \\
\hline Hydrocortisone, $(\times 1)$ & 100 & Saline rectal drip & $\begin{array}{l}\text { Best penetration, no } \\
\text { side effects }\end{array}$ & Cumbersome, unstable & $\begin{array}{l}58 \\
73\end{array}$ & $\begin{array}{l}69 * \\
52 \dagger\end{array}$ \\
\hline $\begin{array}{l}\text { Prednisolone 21-phosphate } \\
\quad(\times 5)\end{array}$ & 20 & Plastic enema bag & $\begin{array}{l}\text { Convenient, stable, } \\
\text { minimal side effects }\end{array}$ & $\begin{array}{l}\text { Distasteful to some } \\
\text { patients }\end{array}$ & $\begin{array}{r}20 \\
100\end{array}$ & $\begin{array}{l}75^{*} \\
88 \dagger\end{array}$ \\
\hline Betamethazone $(\times 50)$ & $5-10$ & Plastic enema bag & Convenient, stable & $\begin{array}{l}\text { Consistent, severe } \\
\text { side effects }\end{array}$ & 48 & $82 \ddagger$ \\
\hline Betnovate $(\times 1 / 50)$ & $2-5$ & $\begin{array}{l}\text { Plastic enema bag } \\
\text { or tablet }\end{array}$ & Convenient & $\begin{array}{l}\text { Insoluble, incidence of } \\
\text { side effects unknown }\end{array}$ & \multicolumn{2}{|c|}{ Under evaluation } \\
\hline $\begin{array}{l}\text { Oral prednisone } \\
\text { Topical hydrocortisone }\end{array}$ & $\begin{array}{r}20 \\
100\end{array}$ & $\begin{array}{l}\text { Enema and } \\
\text { tablets }\end{array}$ & Convenient & $\begin{array}{l}\text { Side effects from oral } \\
\text { steroid }\end{array}$ & 56 & $65 t$ \\
\hline
\end{tabular}

Figures in parentheses refer to relative potencies of steroids (hydrocortisone $=1$ )

*Truelove (1958, 1959, 1960a, b). †Watkinson (1958, 1961a, b, 1962).

$\ddagger$ Matts (1960), Matts \& Gaskell (1961) and Matts (1962). 
Combined topical and systemic steroids

A combination of topical and systemic steroid therapy was first advocated by Truelove (1960a) and it was later shown by a controlled trial that a combination of hydrocortisone retention enemata and prednisone by mouth would induce symptomatic remissions in $65 \%$ of a group of fifty-eight patients so treated, with mucosal improvement in $79 \%$ (Truelove et al., 1962).

\section{Treatments under evaluation}

\section{Immunosuppressive agents}

The temporary improvements induced in autoimmune diseases such as disseminated lupus erythematosus by the use of immunosuppressive agents made it not unreasonable to use these in the treatment of ulcerative colitis, as was first advocated by Bean in Australia in 1962. While these drugs can suppress immune reactions they can also unpredictably produce marrow depression with resulting anaemia, leucopenia and thrombocytopenia which do not aid the physician in treating a condition with well-established infective and haemorrhagic features.

Two groups of Australian workers (Bean, 1966; MacKay, Wall \& Goldstein, 1966) have used such drugs as 6-mercaptopurine, busulphan or azothioprine (Imuran) to treat fourteen colitic patients, twelve of whom showed immediate and eleven sustained improvement and in whom serious marrow depression was rare. While eight out of ten patients, treated with azothioprine in Professor Kirsner's clinic in Chicago, showed initial improvement this was only sustained in one patient and difficulties with marrow depression have led this group to no longer advocate this form of therapy (Bowen et al., 1966 ; Kirsner, personal communication 1967). The rapid death of a young colitic patient from agranulocytosis following treatment with azothioprine led Jones and others (1966) to emphasize the potential dangers of this form of treatment.

The results, therefore, in twenty-five patients treated to date have been far from impressive and the routine use of these particularly dangerous drugs cannot be recommended at present in ulcerative colitis until further careful prolonged assessments have been made in research centres used to handling colitic patients.

\section{Rectal hypothermia}

The control of haemorrhage from the stomach and from the prostatic bed by local freezing led a group of Rumanian workers to freeze the rectal mucosa in nine patients with 'ulcerative and haemorrhagic proctocolitis' with immediate improvement in all cases which was sustained for periods of 3-18 months (Mandache et al., 1965). This trial was uncontrolled and the method requires investigation. It might have a place in controlling massive rectal bleeding in the few colitic patients in which it occurs.

\section{Leucotomy}

Leucotomy or selective pre-frontal electrocoag $-\frac{\hat{T}}{0}$ ulation has been advocated and successfully practiced in a Swiss clinic in colitic patients (Wissmer, 1959). Again critical assessment and $\mathbb{Q}$ prolonged follow up would be required before this drastic and irreversible form of therapy could be advocated. The same criticisms can be $\vec{\circ}$ made about the value of electric shock therapy $\overrightarrow{\vec{\omega}}$ or prolonged narcosis also advised in ulcerative colitis.

\section{Maintenance treatment}

Having controlled acute attacks of colitis the physician next tries by some form of maintenance $\vec{G}$ treatment to prevent relapses or complications of

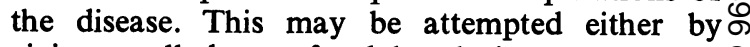
giving small doses of sulphasalazine or small or 음 large doses of steroids on a long term basis.

\section{Sulphasalazine}

Sulphasalazine given in doses of four table $\vec{\Phi} \underset{\mathbb{D}}{\mathbb{Q}}$ daily has been claimed to keep between on $\frac{3}{5}$ half and three-quarters of large groups of patiends in remission for periods of $1-5$ years with infre $\overrightarrow{0}$ quent side effects (Svartz, 1956; Moertal \& Bargen, 1959 ; Watkinson, 1962). Such trials wet? however uncontrolled and the ability of small maintenance doses of sulphasalazine to prevent colitic relapses has only recently been proved by a controlled trial (Misiewicz et al., 1965). In this $\frac{0}{\mathbb{D}}$ trial two groups of similar colitic patients $\varrho$ received either sulphasalazine $0.5 \mathrm{~g}$ four times $\overline{\bar{O}}$ daily or identical dummy tablets over a 12month follow up period. Remissions were maintained in two-thirds of these receiving sulphasalazine and in less than one-quarter of those receiving inert therapy representing a significant advantage for the drug. No side effects were observed. Sulphasalazine emerges as a drug capable in moderate maintenance dosage of preventing colitic relapses in a significant proportion of those treated.

\section{Corticosteroids}

In attempting to prevent colitic relapse with steroids the physician may either give large doses of steroids in sufficient amounts to suppress the $N$ disease accepting high incidence of induced $\underset{\omega}{N}$ side-effects (Spencer et al., 1962). Alternatively an attempt may be made by small maintenance 0 doses of steroids to control the disease accepting 
an appreciable relapse rate and recourse to surgery but avoiding steroid complications (Watkinson, 1966).

While large maintenance doses of cortisone or ACTH given by the Chicago workers kept twothirds of their 340 colitic patients in remission or good health for long periods with a low mortality and recourse to surgery, side effects developed in $85 \%$ of those treated. These included psychological upset $(16 \%)$ diabetes or glycosuria $(12 \%)$ serious electrolyte upsets (12\%) osteoporosis $(4 \%)$ melaena or peptic ulcer $(4 \%)$ while nine deaths could be directly attributed to steroid therapy. The authors felt that good control of the disease was adequate compensation for the side-effects encountered and remain keen advocates of long term large dosage steroid treatment.

Unfortunately, there is no evidence to suggest that small doses of steroids prevent colitic relapses. One controlled trial (Truelove \& Witts, 1959) failed to show any difference in relapse rates in two groups of colitic patients followed for a year receiving either cortisone or identical dummy tablets. A second controlled trial (Lennard-Jones et al., 1965) treated two comparable groups of colitic patients with either $15 \mathrm{mg}$ of prednisone daily or with identical inert tablets. Even though larger doses of steroids were used, inducing side-effects in one quarter of the patients treated, by the end of 6 months identical relapse rates occurred in both groups, namely in eighteen of thirty-two patients receiving prednisone and in seventeen of thirty controls.

Regrettably, therefore, there is no fully controlled evidence that prolonged treatment with small or large doses of steroids influence the natural history of ulcerative colitis, though in individual cases both patient and physician may consider them of value.

\section{Modifications of treatment in relation to severity, extent, clinical pattern and complications of colitis}

Medical treatment has had to be modified with increasing knowledge of the factors affecting the prognosis of ulcerative colitis, namely, the severity of the attack, the extent of the disease, the age of the patient and the presence of associated colonic and systemic complications.

\section{Severity}

\section{Acute fulminating colitis}

Fulminating colitis is a serious medical emergency with a high mortality and frequently requires surgical intervention. Depressing mortal- ities have been reported: between 28 and $50 \%$ by Lennard-Jones \& Vivian (1960) and by Goulston et al. (1960) and there is evidence to suggest that modern treatment has not much reduced the mortality in that type of case (Edwards \& Truelove, 1964).

The management of this type of case is, therefore, one of extreme urgency. Frequently lamentable delay in diagnosis occurs, the patient having been investigated at home or in an infectious diseases hospital as a possible case of a dysenteric illness. While it is vital by stool culture to exclude this possibility, in cases where these prove negative early sigmoidoscopy together with a plain abdominal X-ray will make the true state of affairs apparent and the patient should be urgently transferred to a general medical ward where he can be reviewed daily by both physician and surgeon. Strict bed rest and sedation are enforced, colonic rest promoted by either withholding fluids by mouth or giving a fluid diet, parenteral fluids are administered liberally, the replacement of potassium being particularly important, and liberal blood transfusions are almost always necessary. Adequate vitamin replacements and parenteral feeding are often required. The patient should be given sulphasalazine by mouth, 1-2 $\mathrm{g}$ four times daily, and large doses of steroids parenterally. In this type of case ACTH or cortisone should be given intravenously initially supplemented by intramuscular doses later. Attempts should also be made to administer steroids topically in the form of a rectal drip of hydrocortisone or retention enemata of prednesol which if retained adequately will speed recovery (Truelove, 1960b). Fulminating cases are often markedly improved by a short course of an antibiotic, such as penicillin and streptomycin, ampicillin or erythromycin given parenterally. In addition to this intensive nursing and medical care, levels of haemoglobin, haematocrit and electrolytes should be estimated daily in order to plan the parenteral therapy given. Daily assessments jointly by physician and surgeon are continued and attempts were formerly made to allow this medical treatment to have its full effect over 10-14 day period. However, when this principle was applied to 124 patients with severe colitic attacks in Leeds between 1952 and 1963, only $52 \%$ went into remission, $5 \%$ died under medical treatment and $32 \%$ required emergency surgery, the overall mortality remaining depressingly high at $11.3 \%$ (Goligher et al., 1967).

Accordingly, it was decided, for a trial period, to invoke surgical aid at a much earlier stage in these severe attacks unless there was evidence of a rapid and unequivocal improvement on max- 
imal medical treatment. Indications for urgent surgery can be briefly summarized as continuing massive haemorrhage, perforation, sudden deterioration in the general condition of the patient, and after 2 or 3 days of conservative management in elderly subjects and within 4-5 days of initiation of therapy in younger patients. The results of this policy in eighty-one patients with severe attacks treated in Leeds between 1964 and 1966 were quite dramatic.

Remissions occurred with similar frequency, namely in $47 \%$, and no deaths occurred under medical treatment. Urgent surgery was undertaken in half these patients and the overall mortality was reduced to $1 \cdot 3 \%$. While this was not in any way a controlled trial, this experience and that of others (Gallagher et al., 1962), would suggest that surgery has an increasing role to play in fulminating attacks of ulcerative colitis until some improved type of medical treatment can be devised.

\section{Chronic ulcerative colitis}

Here the physician has adequate time to apply the full therapeutic programme previously described, remembering however, that at any time further fulminating attacks may occur, that the disease tends to extend and that as the years pass on an increasing number of complications may develop. There seems to be little tendency for the disease to burn itself out so that surgery will often be required for the invalidism induced by recurring attacks of the disease or the development of colonic or systemic complications.

\section{Extent of colonic involvement}

The management of ulcerative colitis is materially affected by the extent of colonic involvement.

\section{Proctocolitis}

These patients are mainly troubled by rectal bleeding and by constipation and by a bloodstained rectal discharge. They seldom become acutely ill save from the effects of anaemia. Bulk-forming laxatives, senokot or milk of magnesia should be given in sufficient amounts to promote a bulky soft daily bowel action. If rectal bleeding continues suppositories of either sulphasalazine or prednisolone should be inserted on waking and retiring. For more intractable cases topical treatment with retention enemata of prednisolone should be tried and rarely short courses of sulphasalazine and prednisone have to be given orally.

Iron therapy is often required to correct the anaemia present.

\section{Distal proctocolitis}

Patients with involvement of the pelvic and descending colon can get colitic attacks of all $\bar{z}$

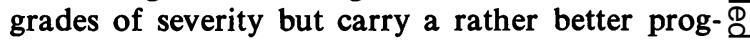
nosis than those with total involvement and are $c$ relatively free from the risk of malignant change. Medical trestment by dietary means, by sulpha- $\stackrel{\vec{P}}{\rightarrow}$ salazine and by steroids topically and systemically, can therefore be safely persisted in for long $\frac{\bar{\sigma}}{\bar{N}}$ periods. Regrettably the disease in many cases $\frac{\Phi}{\vec{T}}$ tends to spread proximally making the need for $\stackrel{\mathbb{\Omega}}{\varrho}$ elective surgery to be kept constantly under re- œ view.

\section{Colitis with total colonic involvement}

While many of these patients can be kept well through the years on maintenance treatment and many have spontaneous remissions of symptoms, 3 studies of the natural history of the condition have shown that these are the patients most likely $\vec{c}$ to develop relapses and complications of the $\vec{G}$ colitis itself and as the years pass to be increasingly prone to the risk of malignant change in the colon. Furthermore, the disease is unlikely to become less extensive under the influence of $\rightarrow$ medical treatment. In these circumstances the $\mathcal{D}$ physician should not persist with medical treafit ment indefinitely and when total colonic involve $\frac{\mathbb{D}}{3}$ ment has been demonstrated unequivocally radio: logically should explain the risks at stake to the patient and elective proctocolectomy should advised. Patients are usually, understandabl reluctant to accept this advice while they afe symptom-free. They should be warned that surgery is desirable and pressure put upon them to accept surgery when a relapse occurs.

\section{Segmental colitis and entero-colitis}

The difficulties in distinguishing ulcerative $\overrightarrow{\overrightarrow{0}}$ colitis and Crohn's disease of the colon and small 3 intestine have been emphasized elsewhere. If symptoms and signs of a malabsorption state are present or if severe unusual perianal disease $\overline{0}$ occurs and the rectum looks normal on sigmoid- 3 . oscopy, Crohn's disease should be suspected and $\frac{0}{3}$ medical treatment persisted in for as long as possible. Here dietary measures, particularly the $\frac{\delta}{3}$ restriction of fat and the long-term usage of

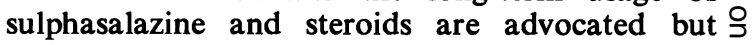
still have to be shown to modify the long-term $\vec{D}$ course of the condition. In many cases the development of obstruction or internal fistula forma- $N$ tion or the development of perianal disease will make surgery inevitable.

If true segmental ulcerative colitis is suspected $\underset{\omega}{N}$ and the rectum appears normal on sigmoidoscopy, early surgery should be advised and the diseased segment resected followed by ileo-colic 
or colo-colic anastomosis. If medical treatment is persisted in there is a tendency for the disease to spread distally, eventually to involve the rectum, making the less acceptable operation of total proctocolectomy and ileostomy necessary.

\section{Clinical pattern of colitis}

\section{Age of the patient}

Additional problems in the management of ulcerative colitis occur at the extremes of life in children and in the elderly; the particular problem in children is that colitis in the first decade is a cause of infantilism with physical retardation of growth and a delayed onset of puberty. Once total colonic involvement has occurred these children are just as susceptible to relapses and complications and to malignant change as are adults and because of the early onset of symptoms develop them at a very tender age (Rosenqvist et al., 1959).

While medical treatment follows a similar pattern to that for adults, particular attention to the protein and calorie needs of the patient is necessary and the correction of anaemia is vital if the chance of physical retardation is to be reduced. Emotional conflicts seem more common in colitic children who often have aging, ambitious and over-attentive parents who often make excessive academic demands on children of average ability. Treatment of the whole family by explanation and common sense psychotherapy is often necessary. Tragically physical retardation, together with extensive and long-standing disease, often make proctocolectomy and ileostomy inevitable. The operation is usually well tolerated by the child and surprising degrees of growth and weight gain will often follow operation.

The serious prognosis of acute colitic attacks in elderly patients is emphasized elswhere making it necessary to consider emergency colectomy at a much earlier stage than in younger patients (Goligher et al., 1967). While many lives can undoubtedly be saved in these elderly patients the effects of an ileostomy life in this age group has not yet been studied in detail.

\section{Ulcerative colitis and pregnancy}

The effect of pregnancy on the natural history of colitis together with the effect of colitis on the mother and foetus is described elsewhere, (de Dombal et al., 1965b), where it was shown that pregnancy had little effect on the relapse rate of colitis compared to a control population and the relapse occurred most commonly during the first trimester or during the immediate post-partum period. The incidence of abortion and foetal abnormality was below that which might have been expected suggesting that neither the colitis nor its treatment with sulphasalazine or steroids had affected the foetus.

Statistically, therefore, there are few grounds for advising termination in pregnancy. However, each case has to be assessed individually and the desire for the child assessed against the effect of the colitic attack on the mother. If the child is wanted improvement usually occurs, particularly in the second and third trimesters. There is a case for increasing full supportive treatment with sulphasalazine and steroids during the first 3 months of pregnancy and for 2 or 3 months after delivery. If the child is unwelcome relapse is likely and if the mother's health deteriorates rapidly in the first trimester, termination of pregnancy may have to be advised often with dramatic cessation of symptoms. The ability of colitic patients to conceive and be delivered of normal children after colectomy and ileostomy is emphasized by the authors.

Effects of complications of the colitis on medical treatment

The serious colonic complications of colitis such as perforation, toxic megacolon and massive rectal haemorrhages are indications for urgent colectomy, continuing medical treatment being both unwise and dangerous. Similarly extensive stricture formation and gross pseudopolyposis with total colonic involvement make it extremely unlikely that any form of medical treatment will be successful and in these circumstances elective proctocolectomy and ileostomy are advised. Similarly severe perianal disease may be worsened by medical treatment particularly by steroids and will sway the physician again towards advising surgery.

Of the systemic complications skin conditions and recurrent attacks of colitic arthritis may prove extemely refractory to medical treatment but are usually cured by colectomy. Iritis, liver disease and sacro-ileitis however are unlikely to be improved by colectomy and in these cases intensive treatment of the colitis by dietary means, steroids and sulphasalazine should be persisted in (Watkinson, 1968).

\section{Conclusions}

In this paper the medical treatment of ulcerative colitis has been reviewed and its ability to terminate acute attacks, prevent relapse and complications assessed. The fact that medical treatment fails sometimes to achieve all these objectives makes it vital that the cases be managed jointly by physician and surgeon both in the 
acute attack and in long-term management the possibility of operation being kept constantly under review.

\section{References}

ANDRESEN, A.F.R. (1942) Ulcerative colitis: an allergic phenomenon. Amer. J. dig. Dis. 9, 91.

BARGEN, J.A. (1948) Evaluation of newer therapy of ulcerative colitis. South. Med. J. 41, 646.

BARgen, J.A. (1961) Colitis, chronic ulcerative. Current Therapy (Ed. by Harvard F. Conn), p. 219. Saunders, Philadelphia.

Baron, J.H., Connell, A.M., Lennard-Jones, J.E. \& JoNES, F.A. (1962a) Sulphasalazine and salicylazosulphadimidine in ulcerative colitis. Lancet, i, 1094.

Baron, J.H., Connell, A.M., Kanaghinis, T.G., LennardJoNES, J.E. \& JoNES, F.A. (1962b) Outpatient treatment of ulcerative colitis. Comparison between three doses oral prednisone. Brit. med. J. ii, 441 .

BEAN, R.H.D. (1962) The treatment of chronic colitis with 6-mercaptopurine. Med. J. Aust. 2, 1175.

BEAN, R.H.D. (1966) Treatment of ulcerative colitis with antimetabolites. Brit. med. J. i, 1081.

Bowen, G.E., Irons, G.V., Rhodes, J.B. \& Kirsner, J.B. (1966) Early experiences with azothioprine in ulcerative colitis. J. Amer. med. Ass. 195, 460.

Braders, A.C. \& Bargen, J.A. (1960) Salicylazo-sulphadimethyl-pyrimidine (Azudimidine) in the treatment of ulcerative colitis. Writings and Reports, Scott \& White Clinic, 3, 229.

Brooke, B.N. (1956) Cortisone and ulcerative colitis. An adverse effect. Lancet, ii, 1175.

Crohn, B.B. \& YaRnis, H. (1951) Present trends in treatment of ulcerative colitis. N.Y. Med. J. 51, 2129.

DE Dombal, F.T., Watts, J.McK., Watkinson, G., \& Goligher, J.C. (1965a) Intraperitoneal perforation of the colon in ulcerative colitis. Proc. roy. Soc. Med. 58, 713.

de Dombal, F.T., Watts, J.McK., Watkinson, G. \& Goligher, J.C. (1965b) Ulcerative colitis and pregnancy. Lancet, ii, 599.

Dick, A.P., Grayson, M.J., Carpenter, P.G. \& Petrie, A. (1964) Controlled trial of sulphasalazine in the treatment of ulcerative colitis. Gut, 5, 437.

Edwards, F.C. \& Truelove, S.C. (1964) The course and prognosis of ulcerative colitis. Gut, $5,1$.

Gallagher, N.D., Goulston, S.J.M., WyndhaM, N. \& MorRow, W. (1962) The management of fulminant ulcerative colitis. Gut, 3, 306.

Gill, A.M., Otaki, A.T., Daly, J.R. \& Spencer-Peet, J. (1965) Oral betamethasone 17-valerate in chronic ulcerative colitis and Crohn's disease. Brit. med. J. ii, 29.

Goldgraber, M.B., Kirsner, J.B. \& Palmer, W.L. (1957) The role of ACTH and adrenal steroids in perforation of the colon in ulcerative colitis. A clinicopathological study. Gastroenterology, 33, 434.

Goligher, J.C., DE Dombal, F.T., Graham, N.G. \& WATKINSON, G. (1967) Early surgery in the management of severe ulcerative colitis. Brit. med. J. ii, 193.

Goulston, S.J.M., RANkin, J.G., Boden, R.W. \& Morrow, A.W. (1960) Fulminant ulcerative colitis. Quart. J. Med. N.S. 29,375 .

Grace, W.J. \& WolfF, H.G. (1951) Treatment of ulcerative colitis. J. Amer. med. Ass. 146, 981.

Grace, W.J. \& GrahaM, D.T. (1952) Relationship of specific attitudes and emotions to certain bodily disease. Psychosom. Med. 14, 243.
GroEN, J.J. (1961) Panel discussion on ulcerative colitis. 을 Proc. Int. Cong. of Gastroenterology (Leyden), 1960, § page 511.

Jones, F.A., Lennard-Jones, J.E., Hinton, J.M. \& Reeves, W.G. (1966) Dangers of immunosuppressive drugs in $\varrho$ ulcerative colitis. Brit. med. J. i, 1418.

KASISCH, A.M. (1963) Clinical evaluation of nandrolene $\Rightarrow$ phenopropionate in patients with gastro-intestinal disease. $\overrightarrow{9}$ Amer. J. Gastroenterol. 40, 628.

LENNARD-JoNeS, J.E. \& Vivian, A.B. (1960) Fulminating ulcerative colitis. Recent experience in management. Brit. med. J. ii, 96.

LenNARD-Jones, J.E., Longmore, A.J. Newell, A.C., $\overparen{\mathbb{D}}$ Wilson, C.W.E. \& JoNes, F.A. (1960) An assessment of prednisone, salazopyrin and topical hemisuccinate used $\infty$ as outpatient treatment in ulcerative colitis. Gut, 1, 217. $\overrightarrow{0}$ Lennard-Jones, J.E., Baron, J.H., Connell, A.M. \& . JONES, F.A. (1962) A double blind controlled trial of $\overrightarrow{\vec{\omega}}$ prednisolone-21-phosphate suppositories in the treatment $\vec{\omega}$ of idiopathic proctitis. Gut, 3, 207.

Lennard-Jones, J.E., Misiewicz, J.J., Connell, A.M., BARON, J.H. \& JoNes, F.A. (1965) Prednisone as maintenance treatment for ulcerative colitis in remission. Lancet, i, 188.

MCDermotT, J.F., JR, JohN, F. \& FinCh, S.M. (1964) G Ulcerative colitis, physician teamwork in the treatment. $G$ Clin. Paediat. (Phila), 3, 75.

MaCKay, I.R., WALl, A.J. \& Goldstein, G. (1966) هึ Response to azothioprine in ulcerative colitis. Amer. 음 J. dig. Dis. 2, 537.

Mandache, F.L., Pradescu, Y., Mateescu, D., Lutesc $\bar{\theta}$ I., Korer, G., Stanicelescu, P. \& Mateica, M. (196\$ Rectal hypothermia. J. int. Coll. Surg. 44, 128.

MATTS, S.G.F. (1960) Local treatment of ulcerative colit with prednisolone-21-phosphate enemata. Lancet, i, 517.0

MATTS, S.G.F. \& GASKELL, K.H. (1961) Retrograde colonic $\mathbb{D}$ spread of enemata in ulcerative colitis. Brit. med. ii, 614 .

MATTS, S.G.F. (1962) Betamethazone enemata in ulceratio colitis. Gut, 3, 312.

MisiewiCZ, J.J., LenNaRd-Jones, J.E., Connell, A.M., BARON, J.H. \& Jones, F.A. (1965) Controlled trial of sulphasalazine in maintenance therapy for ulcerative $\bar{\partial}$ colitis. Lancet, i, 185.

Moertal, C.G. \& BARgen, J.A. (1959) A critical analysis of the use of salicylazosulphapyridine in chronic ulcerative colitis. Ann. intern. Med. 51, 879.

MorRison, L.M. (1963) Response of ulcerative colitis to therapy with salicylazosulphapyridine. J. Amer. med. Ass. 151, 366.

MurRay, C.D. (1930) Psychogenic factors in the aetiology of ulcerative colitis and bloody diarrhoea. Amer. J. med. Soc. 180, 239.

Patterson, M., McGivney, J., Ong, H. \& Drake, A. (1965) Topical steroid therapy of ulcerative colitis. Gastroenterologica, 103, 141.

Paulley, J.W. (1950) Ulcerative colitis. A study of 173 cases. Gastroenterology, 16, 566.

Rosenqvist, H., LAGercrantz, R., ÖhrLING, H. \& EdLING, N. (1959) Ulcerative colitis and carcinoma coli. Lancet, i, 906.

Rowe, A.H. (1942) Chronic ulcerative colitis-allergy in its aetiology. Ann. intern. Med. 17, 83.

Spencer, J.A., Kirsner, J.B., MylnaryK, P., Reed, P.I. 命 \& PAlmer, W.L. (1962) Immediate and prolonged therapeutic effect of corticotrophin and adrenal studies $O$ in ulcerative colitis. Observations in 340 cases for periods $\mathrm{N}$ up to ten years. Gastroenterology, 42, 113.

SPENCER, J.A. \& KIRSNER, J.B. (1962) Experiences with long term courses of adrenal steroid therapy in ulcerative colitis. Gastroenterology, 42, 669. 
SvarTz, N. (1941) Ett. Nytt. sulforamid preparat. in Nord. Med. 9, 554.

Svartz, N. (1956) The treatment of ulcerative colitis. Gastroenterologica, 86, 683.

Svartz, N. (1961) Panel discussion on ulcerative colitis. Proc. Int. Cong. Gastroenterology. (Leyden), 1960, page 484.

Truelove, S.C. (1956) Treatment of ulcerative colitis with local hydrocortisone. Brit. med. J. 2, 1267.

Truelove, S.C. (1958) Treatment of ulcerative colitis with local hydrocortisone hemisuccinate sodium. A report on a controlled therapeutic trial. Brit. med. J. ii, 1072.

Truelove, S.C. (1959) Suppository treatment of haemorrhagic proctitis. Brit. med. J. i, 955.

Truelove, S.C. (1960a) Systemic and local corticosteriod therapy in ulcerative colitis. Brit. med. J. i, 464.

Truelove, S.C. (1960b) Local corticosteriod treatment in severe attacks of colitis. Brit. med. J. ii, 102.

Truelove, S.C. (1961) Ulcerative colitis provoked by milk. Brit. med. J. i, 154.

Truelove, S.C., Watkinson, G. \& Draper, G. (1962) Comparison of corticosteroid and sulphasalazine therapy in ulcerative colitis. Brit. med. J. ii, 1708.

Truelove, S.C. \& WitTs, L.J. (1955) Cortisone in ulcerative colitis. Final report on a therapeutic trial. Brit. med. J. ii, 1041.

Truelove, S.C. \& Witts, L.J. (1959) Cortisone and corticotrophin in ulcerative colitis. Brit. med. J. i, 387.
Watkinson, G. (1958) Treatment of ulcerative colitis with topical hydrocortisone hemisuccinate sodium. A controlled therapeutic trial employing restricted sequential analysis. Brit. med. J. ii, 1077.

WATKInSON, G. (1961a) Medical management of ulcerative colitis. Brit. med. J. i, 147.

Watkinson, G. (1961b) Panel discussion on ulcerative colitis. Proc. Int. Cong. Gastroenterology (Leyden), 1960, page 486.

Watkinson, G. (1962) The medical treatment of ulcerative colitis. Postgrad. med. J. 38, 688.

WATKINSON, G. (1966) Corticosteroids in ulcerative colitis. Proc. 9th Int. Cong. Int. Med., 1966. Excerpta Medica.

Watkinson, G. (1968) The systemic complications of ulcerative colitis. Postgrad. med. J. 44, 693.

WATTS, J.MCK., DE DOMBal, F.T., WaTKInSON, G. \& GoligheR, J.C. (1966a) The early course of ulcerative colitis. Gut, 7, 16.

WaTTS, J.MCK., DE Dombal, F.T., Watkinson, G. \& GoligheR, J.C. (1966b) Long term prognosis of ulcerative colitis. Brit. med. J. ii, 1447.

Wright, R. \& Truelove, S.C. (1965a) A controlled therapeutic trial of various diets in ulcerative colitis. Brit. med. J. ii, 138.

Wright, R. \& Truelove, S.C. (1965b) Circulating antibodies to dietary proteins in ulcerative colitis. Brit. med. J. ii, 142.

Wissmer, B. (1959) Neurological treatment of ulcerative colitis. Proc. Ist Ann. Meeting Bockus Internat. Soc. Gastroenterol. Philadelphia. 